\title{
Identification of the Fetal Liver Cytochrome CYP3A7 in Human Endometrium and Placenta
}

\author{
John D. Schuetz, ${ }^{\star \bullet}$ Scott Kauma, ${ }^{\star}$ and Philip S. Guzelian * \\ ${ }^{*}$ Departments of Medicine and ${ }^{\ddagger}$ Obstetrics and Gynecology, Medical College of Virginia, Richmond, Virginia 23298-0267; and \\ ${ }^{s}$ Department of Pharmaceutical Sciences, St. Jude Research Hospital, Memphis, Tennessee 3810-0318
}

\begin{abstract}
Placenta and endometrium carry out steroidogenic biotransformation reactions such as 6 - $\beta$-hydroxylation of cortisol, a reaction characteristic of the dominant family of cytochromes $\mathbf{P 4 5 0}$ in human liver, CYP3A. To investigate the possible role in these extrahepatic tissues of the CYP3A microsomal hemoproteins, we analyzed placental and endometrial microsomes on Western blots developed with an anti-human CYP3A antibody. We found an immunoreactive 51,500 D protein that migrated between CYP3A3 (HLp) and CYP3A5 (HLp2) identical with CYP3A7 (HFLa). CYP3A7, a form found prominently in human fetal liver microsomes, was first isolated as a liver 16- $\alpha$ dehydroepiandrosterone-sulfate hydroxylase. Northern blot analysis of total RNA isolated from placenta or from endometrium demonstrated a single band that cross-hybridized with a CYP3A7 cDNA. Amplification of the same RNA samples with the use of primers specific for CYP3A7, produced a 552-bp segment that had the predicted size and the same DNA sequence as does liver CYP3A7 cDNA. Hybridizable endometrial CYP3A7 mRNA was detected more frequently (six of seven samples) and in higher amounts ( 12-fold higher $)$ in pregnant compared with nonpregnant women (4 of 12 samples). In addition, during the secretory phase of the menstrual cycle CYP3A7 expression was sixfold higher than in the one sample from the proliferative phase that had detectable CYP3A7 mRNA. Moreover, the amounts of placental and endometrial CYP3A7 mRNA and protein increased substantially from the first to the second trimester of pregnancy. We conclude that placenta and endometrium express the same $\mathbf{P 4 5 0}$ as is found in fetal liver. These tissues represent a previously unrecognized and quantitatively important site for 6 - $\beta$-hydroxylation and 16- $\alpha$-hydroxylation of specific steroid precursors, possibly for protection of the fetus from the toxic effects of endogenous steroids and foreign substrates. (J. Clin. Invest. 1993. 92:1018-1024.) Key words: dehydroepiandrosterone-sulfate • placenta • endometrium • estriol • xenobiotic
\end{abstract}

\section{Introduction}

The cytochromes P450 are a multigene family of microsomal hemoproteins, most abundant in the liver, that play a critical role in the biooxidation of such xenobiotics as drugs, pesticides,

Address correspondence to Dr. P. S. Guzelian, Department of Medicine, Section of Medical Toxicology, University of Colorado Health Sciences Center, Room 723, BRB Building, Box B-146, 4200 East 9th Avenue, Denver, CO 80262.

Received for publication 16 June 1992 and in revised form 24 March 1993.

J. Clin. Invest.

(C) The American Society for Clinical Investigation, Inc.

$0021-9738 / 93 / 08 / 1027 / 07 \quad \$ 2.00$

Volume 92, August 1993, 1018-1024 and carcinogens (1-4) as well as endogenous agents including fatty acids, inflammatory mediators, and steroid hormones ( 5 , 6 ). Although it has been amply documented that several forms of P450 in liver microsomes catalyze the stereospecific hydroxylation of cortisol, testosterone, androstendione, and progesterone (7-11), the physiological importance, if any, of these reactions in the liver in vivo other than as possible accessory disposal pathways is unclear (12). However, the development of sensitive techniques for measuring P450 proteins and mRNAs has led to the recognition that virtually all tissues contain one or more forms of P450 (6) and that these extrahepatic $\mathrm{P} 450$ s are likely to participate in tissue specific-biotransformations.

For example, the placenta is not merely a protective barrier for the fetus but also facilitates maternal-to-fetal transfer of nutritional, metabolic, and hormonal agents and actively synthesizes steroid hormones, particularly estrogens (13). It is believed that estrogen biosynthesis in the placenta uses dehydroepiandrosterone-sulfate (DHEA-s) ${ }^{1}$ a precursor produced in large amounts by the fetal adrenals. In high concentrations, DHEA-s inhibits cell proliferation (14), interferes with cellular respiration (15), promotes cervical ripening (16), and inhibits placental progesterone biosynthesis (17). These events may adversely affect fetal survival. In contrast, the 16- $\alpha$-hydroxylated form of DHEA-s does not inhibit progesterone biosynthesis (17) and may be less toxic to the fetus. Recently, a form of cytochrome P450 termed HFLa (CYP3A7) that has been thought to be expressed in fetal liver exclusively (18-25) was found to catalyze 16- $\alpha$-hydroxylation of DHEA-s (23). One interpretation of this finding might be that 16- $\alpha$-hydroxylation of DHEA-s serves a self protective fetal function confined to the developing liver.

There are some clues, however, that placental tissues could contain cytochromes P450 of the 3A family. Placental tissues readily oxidize cortisol to 6 - $\beta$-hydroxycortisol, an activity associated with cytochromes of the $3 A$ family $(7,9)$. Such a function might explain the high levels of 6 - $\beta$-hydroxycortisol in the amniotic fluid $(26,27)$. Even though placental tissues gave no evidence for 16- $\alpha$-hydroxylation of DHEA-s in early studies (12), a recent study found that placental cultures can, in the absence of exogenous steroid precursors, synthesize both the 16 $\alpha$-hydroxylated form of DHEA-s and estriol (28). Because the amounts of putative CYP3A that catalyze these reactions might be low or might vary with placental development and

\footnotetext{
1. Abbreviations used in this paper: Under the recommended P450 gene nomenclature system (6) CYP3A3 refers to the human glucocorticoid inducible $\mathrm{P} 450$ previously designated, $\operatorname{HLp}(33) ; C Y P 3 A 4$ refers to the $\mathrm{P} 450$ previously designated $\mathrm{Nf}(40)$; CYP3A5 refers to the second member of the human glucocorticoid inducible P450 gene family, previously designated HLp2 (35); CYP3A7 refers to the fetal liver member of the human glucocorticoid inducible P450 family, previously designated, HFLa (24); CYP3A, the cytochrome P450 3A gene family; CYP3A, gene products ( $m$ RNA or proteins) of the cytochrome P450 3A gene family; DHEA-s, dehydroepiandrosterone-sulfate.
} 
because there are four $C Y P 3 \mathrm{~A}$ gene family members each capable of steroid 6- $\beta$-hydroxylation (HLp [CYP3A3]; Nf [CYP3A4]; HLp2 [CYP3A5]; HFLa [CYP3A7]) (6), ${ }^{2}$ we used sensitive and specific immunochemical techniques, PCR, and cDNA probes to investigate whether a CYP3A mRNA is expressed in the placenta and, if so, which CYP3A form. We now report that among CYP3A family members, CYP3A7 alone is expressed in human placenta and endometrium and that the levels of CYP3A7 immunoreactive protein and CYP3A7 mRNA increase during pregnancy and vary during the menstrual cycle.

\section{Methods}

\section{Materials}

Nytran and nitrocellulose were obtained from Schleicher \& Schuell, Inc. (Keene, $\mathrm{NH}$ ); restriction endonucleases were purchased from $\mathrm{Be}-$ thesda Research Laboratories (Gaithersburg, MD). A cDNA for human interleukin-1B (1.4-kb EcoRI fragment) was kindly provided by Dr. S. Haskill, University of North Carolina (Chapel Hill, NC). The cDNA for human placental lactogen was kindly provided by Dr. I. Boime, Washington University (St. Louis, MO). All other reagents were of the highest quality commercially available.

Liver specimens. The human liver specimens were obtained from transplant donor material or from trauma patients at the time of surgery in accordance with protocols approved by the committee for conduct of human research at the Medical College of Virginia ( Richmond, VA). The patients had normal bilirubin and aminotransferase levels. Fetal livers were obtained from fetuses of patients undergoing therapeutic abortions performed between 10 and 16 wk gestation (18).

Placenta and endometrium. Placentas were obtained from women undergoing either therapeutic abortion or term delivery by cesarean section. A total of 23 placental samples were available (16 RNA for Northern Blot, see Fig. $3 B$; three RNA for PCR, see Fig. 2; four microsomal for immunoblot, Table I). Endometrium was obtained from women undergoing therapeutic abortion or hysterectomy for benign conditions. A total of 30 endometrial samples were available from 28 patients. (We prepared RNA from 28 samples [ 26 for Northern blot and 2 for PCR] and microsomes from five samples.) Approval by the committee for conduct of human research was obtained before tissue samples were collected for this study. Placenta and decidualized endometrium from pregnancy terminations or cesarean section were frozen in liquid nitrogen within $10 \mathrm{~min}$ of surgical removal and then stored at $-80^{\circ} \mathrm{C}$. Endometrium from hysterectomy specimens was scraped from the uterine wall with a scalpel and frozen at $-80^{\circ} \mathrm{C}$. A small portion of each endometrial sample was Formalin fixed and paraffin embedded; thin sections were stained with hematoxylin and eosin and were dated by histological criteria as previously described (29). Pregnancy dating was based on a reliable date of the last menstrual period, on the size of the uterus as judged by ultrasonographic examination, or both methods.

\section{Procedures}

Microsomes and immunoblot analysis. Microsomes were prepared and stored as previously described $(18,30,31)$. Protein concentration was determined colorimetrically as previously described $(18,30,31)$. Samples of microsomes containing up to $40 \mu \mathrm{g}$ of protein were subjected to electrophoresis on polyacrylamide gels $(12.5 \%$ acrylamide, $0.2 \%$ bisacrylamide ) containing $0.1 \% \operatorname{SDS}(18,31,32)$. Varying amounts of a standardized sample of microsomes containing a known concentration of CYP3A immunoreactive protein were added in adjacent lanes to permit quantification of immunoreactive CYP3A by densitometric analysis of immunoblots developed with a polyclonal anti-CYP3A antibody (32).

2. Comparisons of the nucleotide and deduced amino acid sequences of $C Y P 3 \mathrm{~A} 3$ (HLp) (33) and CYP3A4 (Nf) (40) indicate that these proteins are highly related.
Screening of fetal liver cDNA library cloned in bacteriophage lambda gtll for CYP3A7 cDNA. Approximately 150,000 recombinants were initially screened under low stringency conditions $(2 \times$ SSC and $0.2 \%$ SDS [wt/vol], $42^{\circ} \mathrm{C} ; \mathrm{SSC}=0.15 \mathrm{M} \mathrm{NaCl}$ and $0.015 \mathrm{M}$ sodium citrate) with the use of a cloned fragment representing the internal portion (bases 171-890) of the CYP3A3 cDNA (33). Positive phage were rescreened by use of this probe. Strongly positive clones were purified by multiple screening of isolated plaques at high stringency $\left(0.1 \times \mathrm{SSC}\right.$ and $\left.0.2 \% \mathrm{SDS}, 52^{\circ} \mathrm{C}\right)$. A single positive clone, which contained a single internal EcoRI restriction site and a 1,566-bp insert (bp 404-1,970 of CYP3A7 [24]), was subcloned into either pGEM $3 Z$ or M13 mp18 or 19 and sequenced as described below.

Northern blot. Total RNA was isolated from specimens by guanidinium thiocyanate-phenol-chloroform extraction (34). The RNA ( 30 $\mu \mathrm{g})$ was fractionated by electrophoresis in a formaldehyde denaturing agarose gel (34) and transferred to nitrocellulose by capillary diffusion and then baked at $80^{\circ} \mathrm{C}$ under vacuum for $2 \mathrm{~h}$. Prehybridization and hybridization with the ${ }^{32} \mathrm{P}$-radiolabeled CYP3A7 cDNA were as described previously (35). The size of the CYP3A7 hybridizing mRNA band was estimated by linear interpolation of $28 \mathrm{~S}(4.9-\mathrm{kb})$ and $18 \mathrm{~S}$ (1.95-kb) RNA standards. The samples of placenta and endometrium used in these studies were not cross-contaminated as judged by the absence of specific markers, placental lactogen mRNA and endometrial interleukin-1B hybridizable mRNA, respectively (34). Northern blots were quantified as described (33). A one-way analysis of variance was used for statistical analysis.

$c D N A$ synthesis and $P C R$ reactions. The first-strand cDNA was synthesized by incubating M-MLV reverse transcriptase with $3 \mu \mathrm{g}$ of total cellular RNA in a buffer containing the following $(\mathrm{mM})$ : 10 Tris$\mathrm{HCl}, \mathrm{pH} 8.3,50 \mathrm{KCl}, 1.5 \mathrm{MgCl}_{2}$, and 1.0 of each deoxyribonucleotide triphosphate. PCR reactions were performed in $100 \mu$ l final volumes consisting of $10 \mathrm{mM}$ Tris- $\mathrm{HCl}, \mathrm{pH} 8.3,50 \mathrm{mM} \mathrm{KCl}, 1.5 \mathrm{mM} \mathrm{MgCl}_{2}$, $0.1 \%$ (wt/vol) gelatin, $0.2 \mathrm{mM}$ of each deoxyribonucleotide triphosphate, $100 \mathrm{pmol}$ each of sense and antisense primer, $600 \mathrm{ng}$ of firststrand cDNA, and 2.5 U Taq polymerase. Oligonucleotides were synthesized on a Cyclone instrument (Biosearch, San Rafael, CA) using $\beta$-phosphoramidite methodology and were purified by HPLC with paired-ion chromatography on an HPLC (model 1400A; Applied Biosystems, Inc., Foster City, CA ) with ultraviolet (UV) wavelength set at $260 \mathrm{~nm}$ and monitored by a UV detector (model 1783A, Applied Bio-

Table I. Quantification of Protein Reacting with Antibody to CYP3A in Human Endometrium and Placenta

\begin{tabular}{ccc}
\hline Sample & Gestational age & $\begin{array}{c}\text { Anti-CYP3A reactive } \\
\text { protein }\end{array}$ \\
\hline Endometrium* & $w k$ & $n$ nol/g protein \\
KK & & \\
5D & 16 & 1.4 \\
DD & 15.4 & 1.7 \\
TR & 14 & $<0.20^{\S}$ \\
8D & 11.5 & $<0.20^{\S}$ \\
Placenta & \\
5P & 10.5 & $<0.20^{\S}$ \\
8P & & \\
CS & 15.4 & 1.5 \\
MH & 11.5 & 1.6 \\
Fetal liver & 12 & $<0.20^{\S}$ \\
& 8 & 0.26 \\
\hline
\end{tabular}

* 30 or ${ }^{\ddagger} 40 \mu \mathrm{g}$, respectively, of microsomal protein was resolved on a 12.5\% PAGE gel. Results are a mean of two separate determinations from samples run in duplicate. ${ }^{8}$ Band was detectable but could not be reliably quantified. 
Table II. Mismatches/Estimated Melting Temperature * for CYP3A7 Oligonucleotides Compared with Other CYP3A Gene Family Members

\begin{tabular}{|c|c|c|c|c|c|c|c|c|}
\hline \multirow[b]{2}{*}{ Oligonucleotides } & \multicolumn{2}{|c|}{ CYP3A7 } & \multicolumn{2}{|c|}{ CYP3A5 } & \multicolumn{2}{|c|}{ CYP3A4 } & \multicolumn{2}{|c|}{ CYP3A3 } \\
\hline & Mismatches & $T_{\mathbf{m}}$ & Mismatches & $T_{\mathbf{m}}$ & Mismatches & $T_{\mathbf{m}}$ & Mismatches & $T_{m}$ \\
\hline & & ${ }^{\circ} \mathrm{C}$ & & ${ }^{\circ} \mathrm{C}$ & & ${ }^{\circ} \mathrm{C}$ & & ${ }^{\circ} \mathrm{C}$ \\
\hline \multicolumn{9}{|l|}{ Primers } \\
\hline CYP3A7 1189-1212 (sense) & 0 & 64 & 4 & 52 & 3 & 58 & 3 & 58 \\
\hline \multicolumn{9}{|l|}{ 5'-ATT-CCA-AGC-TAT-GTT-CTT-CAT-CAT-3' } \\
\hline CYP3A7 1723-1743 (antisense) & 0 & 64 & $\neq$ & \pm & 3 & 54 & 3 & 54 \\
\hline \multicolumn{9}{|l|}{ 5'-AAT-CTA-CTT-CCC-CAG-CAC-TGA-3' } \\
\hline \multicolumn{9}{|l|}{ Internal oligonucleotide } \\
\hline CYP3A7 1587-1613 & $\mathbf{0}$ & 74 & 7 & 48 & 10 & 44 & 5 & 58 \\
\hline 5'-CGT-CTT-CAT-TTC-AGG-GTT-CTA-TTT-GTA-3' & & & & & & & & \\
\hline
\end{tabular}

${ }^{*} T_{\mathrm{m}}$, calculated using the formula of Suggs et al. (36) $T_{\mathrm{d}}=4^{\circ}(G+C)+2^{\circ}(A+T) .{ }^{\ddagger}$ Not determined. CYP3A7 1,720-1,741 extends beyond the end of the CYP3A5 cDNA (35).

systems, Inc.) as described (35). After the addition of $100 \mu$ l of mineral oil, the reactions were heated to $95^{\circ} \mathrm{C}$ for $5 \mathrm{~min}$ and immediately cycled 30 times in a programmable heating block (Coy Laboratory Products Inc., Ann Arbor, MI) through 30 cycles consisting of 1 min of denaturation at $94^{\circ} \mathrm{C}, 5 \mathrm{~min}$ of annealing and extension at $65^{\circ} \mathrm{C}$, and 20 min of extension at $65^{\circ} \mathrm{C}$. In most cases, $10-15 \mu$ l of the PCR reaction product were directly separated through a $0.5 \%$ Nusieve agarose $/ 0.5 \%$ agarose mixture (wt/ vol) and visualized by staining with ethidium bromide. Sizes of the PCR products were estimated from the migration of DNA size markers (123-bp ladder) run concurrently. The PCR products were transferred from gels to Nytran membranes by capillary blotting ( 35 ). Southern-blotted membranes were probed with a ${ }^{32} \mathrm{P}$-labeled hybridization oligonucleotide targeted to a region internal to the PCR reaction product (Table I). Control PCR reactions included water blanks as well as samples in which reverse transcriptase was omitted.

The CYP3A7 primers were chosen to provide maximum discrimination between CYP3A7 and the other human CYP3A gene family members. The primers were: antisense CYP3A7 primer, bases 1,7231,743 of the CYP3A7 sequence (24); sense primer, bases 1,189-1,212; internal oligonucleotide primer, bases 1,586-1,611. It should be noted that the last exon of CYP3A7 begins at bp 1,480, which would, because of the intervening intron, allow easy discrimination between the amplified cDNA and genomic DNA (unpublished observation, Schuetz, J. D.). The mismatches of these primers with the other human CYP3A family members are shown in Table II.

$P C R$ subcloning and DNA sequence determination. The ends of the PCR products were repaired by adding the Klenow fragment ( 5 Kunitz $\mathrm{U})$ of PolI to the PCR reaction after a 10 -min incubation at $95^{\circ} \mathrm{C}$. The enzymatically repaired PCR products were then phenol extracted, precipitated with ethanol, and subcloned in both orientations into SmaI site of M13 (37). Single-stranded M13 was prepared from plaque-purified recombinants to determine the nucleotide sequence of the cloned insert using the method of Sanger et al. (38). Results were confirmed by sequencing each region of the cDNA at least four times. The cloned PCR product that we sequenced matched exactly the nucleotide positions 1,189-1,741 of the published CYP3A7 cDNA sequence as aligned by the Genetics Computer Group GAP Program (39). In contrast, this region of CYP3A7 had 37 mismatches compared with the relevant sequence of $C Y P 3 A 3 / 4(33,40)$.

\section{Results}

Immunoblot analysis of CYP3A in endometrium and placenta. Immunoblot analysis of human endometrial and placental microsomes demonstrated a single CYP3A immunoreactive band of $\sim 51,500 \mathrm{D}$ in both endometrium and placenta (not shown). We extended the immunoblot analysis with samples of human liver microsomes known to contain neither CYP3A5 nor CYP3A7 but only CYP3A3/4 (HL 19) $(32,41,42)$, CYP3A7 (FL) or CYP3A3/4 and CYP3A5 (HL 34). These samples were run in lanes adjacent to endometrial or placental microsomes, which, in some cases, were mixed with an aliquot of HL 19, the sample that only contained CYP3A3/4 (Fig. 1). By comparing the migration patterns for endometrial or placental microsomes with that for a sample of human liver microsomes known to contain CYP3A3/4 plus CYP3A5 (HL 34) but not CYP3A7, we found that the CYP3A immunoreactive band associated with endometrium or placenta migrated between the CYP3A3/4 and CYP3A5 immunoreactive bands (Fig. 1). Finally, the rate of migration of the CYP3A immunoreactive band in endometrial and placental microsomes was identical with that in a sample of human fetal liver microsomes known to contain only CYP3A7 (Fig. 1).

Quantification of CYP3A immunoreactivity in gestational human endometrium and placenta. Immunoreactive protein was detectable in each of the five endometrial and four placental microsomal samples available for analysis (Table I). We carried out a quantitative analysis of our immunoblots, taking the assumption that our polyclonal human anti-CYP3A antibody has equal affinity for the proteins it identifies in placenta, endometrium, and liver. Calculated in this way (Table I) the

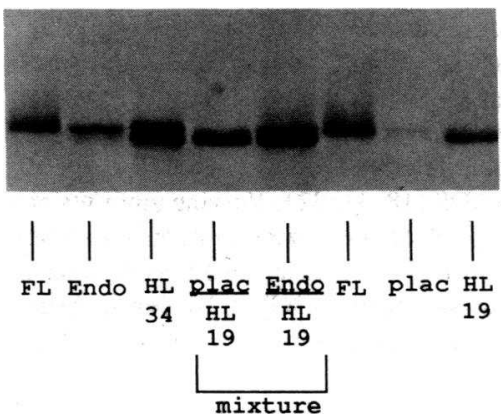

Figure 1. Immunoblot analysis of microsomes from human endometrium and placenta. Microsomes isolated from the indicated specimens of human adult liver ( $H L 34$ or $H L 19$ ), fetal liver $(F L)$, placenta (plac), or endometrium (Endo) were analyzed separately or as mixtures on immunoblots developed with an antibody that recognizes CYP3A proteins as described in Methods. 


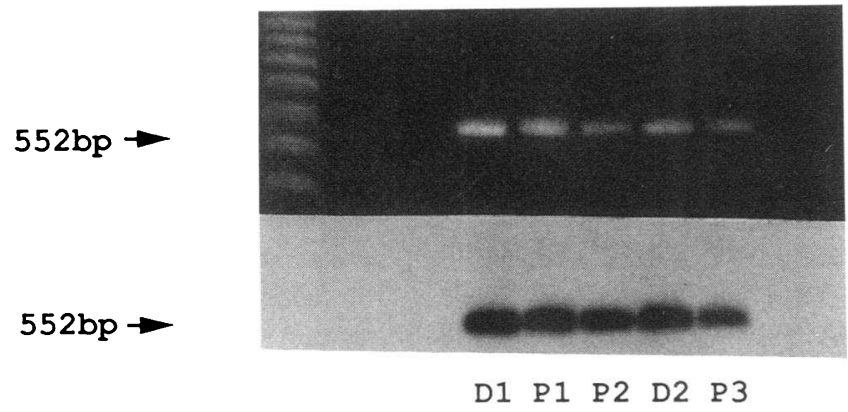

Figure 2. Southern blot analysis of PCR-amplified CYP3A7 mRNA from human endometrium and placenta. Total RNA isolated from samples of either endometrium or placenta was converted to cDNA and amplified by PCR with the use of a primer pair specific for CYP3A7 as described in Methods. Gel electrophoresis was performed on the PCR-amplified samples (top). The gel fractionated PCR product was transferred to Nytran and hybridized with an oligonucleotide specific for the CYP3A7 cDNA (bp 1,587-1,613) (bottom). This oligonucleotide has 10 mismatches with $C Y P 3 A 3$ (33) and 8 mismatches with CYP3A5 (35). Arrows indicate the size of the 552bp PCR product. $D 1, D 2$, endometrial samples; $P 1-P 3$, placenta.

specific concentration of immunoreactive CYP3A, in either endometrium or placenta, was at least sevenfold higher ( $1.4 \mathrm{vs.}$ lower limit of quantification, 0.2 ) in older gestational samples. This increase was specific for CYP3A7 because analysis of these microsomes on immunoblots developed with an antibody directed at another cytochrome P450 family, CYP1A1, revealed positive reactivity, as expected, but no obvious temporal pattern of accumulation of immunoreactive CYP1A1 with increasing gestational age (not shown). The amount of immunoreactive placental and endometrial CYP3A7 protein was 18- to $>155$-fold less than that found in human fetal liver ( Table I). However, because fetal liver is $\leq 20 \%$ of the placental weight during the second trimester, the endometrium and placenta are a quantitatively important site of $C Y P 3 \mathrm{~A} 7$ expression.

$P C R$ analysis of CYP3A $M R N A$ in human endometrium and placenta. Next, we analyzed RNA from endometrium and placenta for the presence of CYP3A mRNA and, on the basis of the results of the immunoblot analysis, we focused on CYP3A7 mRNA, specifically. Recognizing that CYP3A7 mRNA species would not likely be abundant in these tissues, we prepared cDNA copies of the mRNAs in endometrial and placenta RNA specimens and then combined these cDNAs with CYP3A7-specific oligonucleotides (see Fig. 2 legend and Table II) to amplify any CYP3A 7 cDNA that might be present by the sensitive PCR technique (see Methods). We found for both endometrium and placenta that PCR produced a consistent product that was the exact size of the predicted target sequence (Fig. 2). Moreover, the amplified product hybridized with a unique oligonucleotide constructed to bind to a region within the expected amplified CYP3A7 sequence (see Methods). Finally, the DNA sequence of the PCR-synthesized product (Fig. 2) proved to be identical to the published CYP3A7 sequence (24).

Expression of CYP3A7 $\mathrm{mRNA}$ in human endometrium. To determine the pattern of maternal expression of CYP3A7 mRNA, we analyzed RNA isolated from gestational and nongestational endometrium (Fig. $3 \mathrm{~A}$ ) on Northern blots hybridized with a cloned CYP3A7 cDNA (404-1,970 bp) isolated from a human fetal liver cDNA library (see Methods). Among endometrial RNA samples obtained from nonpregnant

\section{A ENDOMETRIUM}

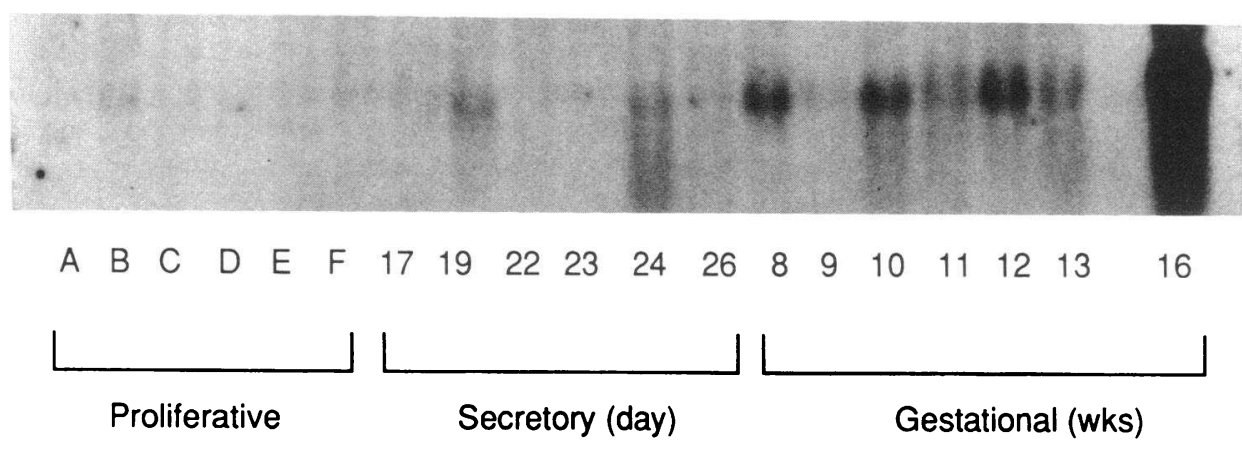

\section{B PLACENTA}

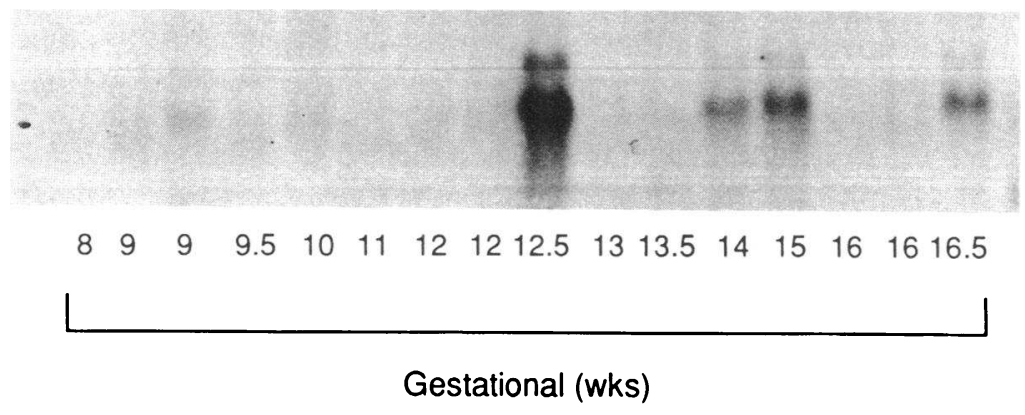

Figure 3. Northern blot analysis of the time course of expression of CYP3A7 mRNA in human endometrium and placenta. $(A)$ Total cellular RNA was isolated from six samples of proliferative $(A-F)$, six of secretory, and seven of decidualized endometrium. The RNA ( 30 $\mu \mathrm{g})$ was fractionated by gel electrophoresis and transferred to nitrocellulose. The filter bound RNA was hybridized with a cDNA for CYP3A7 (bp 404-1,970), (24). (B) Total cellular RNA $(30 \mu \mathrm{g})$ was isolated from 16 samples of human placenta as described in Methods. The samples are arrayed according to their gestational age. The filters were hybridized with a cDNA to CYP3A7 (bp 404-1,971 [24]). 
women during the proliferative phase of the menstrual cycle (Fig. $3 A$, sample $B$ ), we found that only one of six contained hybridizable CYP3A7 mRNA and even this signal was, at best, weakly positive. In contrast, among RNA samples taken during the secretory phase of the menstrual cycle, the frequency of detectable CYP3A7 mRNA was higher (three out of six were positive). The average amount of hybridizing CYP3A7 mRNA in these three was sixfold higher than the value for the single positive sample from the proliferative phase (see Fig. $3 A$ ).

We also found that CYP3A7 mRNA was more frequently detected in endometrial RNA samples from pregnant (Fig. $3 \mathrm{~A}$, gestational, 6 of 7) compared with nonpregnant women (Fig. 3 $A$, proliferative and secretory, 4 of 12) and that the amount of hybridizable endometrial CYP3A7 RNA was higher in the samples from pregnant compared with the positive samples from nonpregnant women (average increase was 12-fold, [ $P$ $<0.05]$ ). A similar RNA analysis carried out on a second set of seven endometrial samples obtained from pregnant patients revealed that five of these were positive for CYP3A7 mRNA (not shown).

Compared with human fetal liver, the amount of endometrial CYP3A7 hybridizable mRNA in pregnancy during the second trimester was $\sim 10 \%$, although in one of our samples (Fig. $3 A$, 16-wk gestational endometrium) the amount of hybridizable CYP3A7 mRNA was similar. The increased amounts of CYP3A7 mRNA associated with gestation appears to be specific because rehybridization of this blot with a $\beta$-actin cDNA probe gave signals of equal intensity among these endometrial samples (data not shown). Moreover, the endometrium did not appear to be contaminated by placenta because endometrial RNA showed no hybridization with a placental lactogen cDNA probe (data not shown) (34). Unfortunately, there were no microsomal samples available from this set of patients analyzed for endometrial CYP3A7 mRNA.

Expression of CYP3A7 $M R N A$ in human placenta. The time course of expression of CYP3A7 mRNA in the placenta was examined by extracting total RNA from 16 placental samples isolated at various times of gestation and analyzing these on Northern blots hybridized with the CYP3A7 cDNA. There was little expression of CYP3A7 mRNA in the first $12 \mathrm{wk}$ (one of eight samples gave a minimal hybridization signal, the others were negative, see Fig. $3 \mathrm{~B}$ ). However, immunoreactive CYP3A protein was present in both of the patients (both were CYP3A7 mRNA negative) for whom microsomal samples were available (C.S., the 8-wk sample, and M.H., the first 12wk sample from left to right, Table I). Second trimester samples were more frequently positive for CYP3A7 mRNA (four of eight samples, Fig. $3 B$ ) and the amounts of CYP3A7 mRNA were greatly increased (the average of these four was about sevenfold higher than the single positive of the first trimester samples). We noted that the apparent size of the hybridizing mRNA species in placenta was the same as that in endometrium and in fetal liver $(2.1 \mathrm{~kb})$, although, in one placental specimen a second hybridizing mRNA $(\sim 2.7-\mathrm{kb})$ species was detected (see $12.5 \mathrm{wk}$, Fig. $3 \mathrm{~B}$ ). This larger form of hybridizable CYP3A7 mRNA may represent use of an alternate polyadenylation signal as has been described for CYP3A4 (43).

\section{Discussion}

These experiments demonstrate that human endometrium and placenta contain CYP3A7, an enzyme that previously was thought to be expressed only in human fetal liver $(24,25,44)$.
Immunochemical techniques demonstrated the appropriate size and immunoreactivity of the CYP3A7 protein accompanied by the appearance of CYP3A7 mRNA documented by PCR, DNA sequence analysis, and Northern blot analysis. Finally, because we have detected a single immunoreactive band with the anti-CYP3A antibody, our immunoblots suggest that CYP3A 7 is the predominant, if not only, CYP3A expressed in the endometrium and placenta. This conclusion is supported by our failure to detect by PCR mRNAs specific for the other CYP3A members (CYP3A4 [40], and CYP3A5 [35], unpublished observations). The greater frequency of detection of CYP3A immunoreactive protein compared with CYP3A7 mRNA could be due to differences in stability of these gene products, although more opportunities to examine both microsomes and RNA from the same patient are needed to investigate this question.

Finding CYP3A7 protein and CYP3A7 mRNA in human endometrium and placenta strengthens the concept that these tissues are important sites for intermediary steroid metabolism. Although we did not measure the metabolic capability of the placental microsomes, the functional activity of placental CYP3A7 can be reasonably inferred from previous studies of placental microsomes or placental explants that document biotransformation reactions $(45,46)$ associated with CYP3A, including formation of 6- $\beta$ hydroxycortisol from cortisol $(7,9)$ and production of estriol (a product of 16- $\alpha$-hydroxylation of DHEA-s) (12). These activities suggest that despite the low concentration of CYP3A7 in the endometrium and placenta relative to that in fetal liver, the large amounts of these extrahepatic tissues makes this enzymatic activity important to intermediary steroid metabolism during pregnancy.

We (47) and others (33) have shown that P450s of the CYP3A family in the liver are inducible. For example, the amount of hepatic CYP3A immunoreactive protein and CYP3A mRNA increases in response to administration of synthetic and natural glucocorticoids $(33,47)$, macrolide antibiotics (48), some antiseizure and antifungal drugs (49), and such environmental agents as polychlorinated biphenyls (PCBs) and organochlorine pesticides (50). We observed an increase in the amounts of CYP3A7 protein and CYP3A7 mRNA in endometrium/placenta associated with increasing gestational age (Table I and Fig. 3, $A$ and $B$ ). We cannot rule out the possibility that the increase could be related in some manner to the source of these tissues (surgical patients) or could be due to enzyme induction by fetal exposure to PCBs, dichlorodiphenyltrichloroethane, and other persistent lipophilic environmental agents that are virtually ubiquitous in the general United States population (51). However, the increase in CYP3A7 immunoreactive protein and mRNA occurred consistently in the second trimester in both placenta and endometrium from different individuals (Table I and Fig. 3, $A$ and $B)$. Furthermore, human CYP1A1 (52), and epoxide hydrolase (53), enzymes that are induced by xenobiotics in the liver, are expressed constitutively in the placenta. We believe a better explanation is that changes in the amounts of endogenous substrates and hormones that can affect $C Y P 3 \mathrm{~A}$ expression in the liver (54) also underlie the developmental regulation of CYP3A7 in the placenta.

Transcription of $C Y P 3 \mathrm{~A} 1$ is controlled by a nonclassical glucocorticoid receptor-mediated process $(47,55)$. Moreover, the synthetic glucocorticoid agonist, dexamethasone, induces CYP3A7 mRNA in the human hepatoblastoma HEPG2 (56, 57) through transcriptional activation of CYP3A7 (unpub- 
lished observations). These observations suggest that steroid hormones and their receptors play a role in the regulation of CYP3A7. The time course of increase in endometrial and placenta CYP3A7 protein and mRNA during pregnancy coincides with an increase in systemic levels of DHEA-s (12), a known substrate for CYP3A7 $(21,23)$. Substrate mediated induction of $C Y P 3 \mathrm{~A} 7$ through DHEA-s bound to its receptor (58) could account for the increased placental and endometrial CYP3A7 mRNA and protein we have found during pregnancy. Another possibility is that circulating glucocorticoids regulate placental/endometrial CYP3A7 just as they do in the liver. Even though systemic glucocorticoid levels do not appreciably change during the intervals of pregnancy we examined (12), the amount of placental glucocorticoid receptor increases from 7- to 12-fold from first to second trimester, a value that, coincidentally, corresponds with the large increase in CYP3A7 mRNA and protein expressed in the placenta (Fig. $3 B$ and Table I). Because the amount of glucocorticoid receptor can be rate limiting for transcriptional activation of a gene by a glucocorticoid (59), it is possible that despite adequate systemic steroids $C Y P 3 \mathrm{~A} 7$ is not transcribed until the amount of glucocorticoid receptor increases. It is intriguing that administration of dexamethasone to pregnant women near term can increase the metabolism of DHEA-s to estriol (60), a conversion that could be controlled by CYP3A7.

We have considered why CYP3A7 is expressed and developmentally regulated in the placenta and endometrium. CYP3A7 was previously thought to be expressed only in fetal liver during early pregnancy $(24,25)$, perhaps to protect the fetus from DHEA-s toxicity (23). When fetal adrenals are stimulated by ACTH in the second trimester, synthesis of DHEA-s increases. Accumulation of excess DHEA-s is associated with intrauterine growth retardation (61), possibly because of inhibition of cell proliferation and differentiation by DHEA-s (62). If the rise in DHEA-s stimulates extrahepatic expression of $C Y P 3 \mathrm{~A} 7$ in the second trimester, this enzyme could provide additional protection for the fetus by forming the nontoxic 16- $\alpha$-hydroxylated DHEA-s metabolite. Another possible adverse effect of DHEA-s is suppression of the synthesis of progesterone, a hormone critical for maintaining pregnancy (12). An increase in placental CYP3A7 could divert the substrate flow to 16- $\alpha$ hydroxylated DHEA-s, a steroid that has no affect on progesterone synthesis (17). Finally, an important but as yet unexplored possibility is that, because some CYP3A forms can both activate and inactivate carcinogens (63-67), the change in the amount of $C Y P 3 \mathrm{~A} 7$ expressed in the reproductive system throughout pregnancy (if this enzyme carries out similar reactions) may play an important role in fetal toxicology during the critical periods in fetal development.

\section{Acknowledgments}

This research was supported by National Institutes of Health grants ESO5744 and ESO4238 and by gifts from the Virginia Environmental Endowment and General Electric foundation.

\section{References}

1. Guengerich, F. P., M. V. Martin, P. H. Beaune, P. Kremers, T. Wolff, and D. J. Waxman. 1986. Characterization of rat and human liver microsomal cytochrome P-450 forms involved in nifedipine oxidation, a prototype for genetic polymorphism in oxidative drug metabolism. J. Biol. Chem. 261:5051-5060.

2. Guengerich, F. P., D. Muller-Enoch, and I. A. Blair. 1986. Oxidation of quinidine by human liver cytochrome P-450. Mol. Pharmacol. 30:287-295.
3. Pichard, L., I. Fabre, G. Fabre, J. Domergue, B. Saint Aubert, G. Mourad, and P. Maurel. 1990. Cyclosporin A drug interactions: screening for inducers and inhibitors of cytochrome P-450 (cyclosporin A oxidase) in primary cultures of human hepatocytes and in liver microsomes. Drug Metab. Dispos. 18:595-606.

4. Conney, A. H. 1982. Induction of microsomal enzymes by foreign chemicals and carcinogenesis by polycyclic aromatic hydrocarbons: G.H.A. Clowes Memorial Lecture. Cancer Res. 42:4875-4917.

5. Ladona, M. G., D. J. M. Spalding, L. Ekman, B. Lindstrom, and A. Rane. 1989. Human fetal and adult liver metabolism of ethylmorphine. Biochem. Pharmacol. 38:3147-3155.

6. Nebert, D. W., D. R. Nelson, M. J. Coon, R. W. Estabrook, R. Feyereisen, Y. Fujii-Kuriyama, F. J. Gonzalez, F. P. Guengerich, I. C. Gunsalus, E. F. Johnson, et al. 1991. The P450 superfamily: update on new sequences, gene mapping, and recommended nomenclature. DNA Cell Biol. 10:1-14.

7. Berliner, D. L., and H. A. Salhanick. 1956. The presence of 6-beta-hydroxylase in human placenta. Clin. Endocrinol. Metab. 16:903-904.

8. Tukey, R. H., S. Okino, H. Barnes, K. J. Griffin, and E. F. Johnson. 1985. Multiple gene-like sequences related to the rabbit hepatic progesterone 21-hydroxylase cytochrome P-450 1. J. Biol. Chem. 260:13347-13354.

9. Lipman, M. M., F. J. Katz, and J. W. Jailer. 1962. An alternate pathway for cortisol metabolism: 6-beta-hydroxycortisol production by human tissue slices. J. Clin. Endocrinol. Metab. 22:268-272.

10. Fabre, G., P. Crevat-Pisano, S. Dragna, J. Covo, Y. Barra, and J.-P. Cano. 1988. Involvement of the macrolide antibiotic inducible cytochrome P-450 LM $3 \mathrm{c}$ in the metabolism of midazolam by microsomal fractions prepared from rabbit liver. Biochem. Pharmacol. 37:1947-1953.

11. Yamazoe, Y., N. Murayama, M. Shimada, and R. Kato. 1989. Thyroid hormone suppression of hepatic levels of phenobarbital-inducible P-450b and P-450e and other neonatal P-450s in hypophysectomized rats. Biochem. Biophys. Res. Commun. 160:609-614.

12. Pritchard, J. A., P. C. Macdonald, and N. F. Gant. 1992. Williams Obstetrics. Appleton-Century-Crofts, Norwalk, CT

13. Branchaud, C. L., C. G. Goodyer, and L. S. Lipowski. 1983. Progesterone and estrogen production by placental monolayer cultures: effect of dehydroepiandrosterone and leuteinizing hormone-releasing hormone. J. Clin. Endocrinol. Metab. 56:761-766.

14. Herrington, D. M., G. B. Gordon, S. C. Achuff, J. F. Trejo, H. F. Weisman, P. O. Kwiterovich, and T. A. Pearson. 1990. Plasma dehydroepiandrosterone and dehydroepiandrosterone sulfate in patients undergoing diagnostic coronary angiography. J. Am. Coll. Cardiol. 16:862-870.

15. Mohan, P. F., and M. P. Cleary. 1989. Dehydroepiandrosterone and related steroids inhibit mitochondrial respiration in vitro. Int. J. Biochem. 21:1103-1107.

16. Sakyo, K., A. Ito, and Y. Mori. 1987. Dehydroepiandrosterone sulfate stimulates collagenase synthesis without affecting the rates of collagen and noncollagen protein synthesis by rabbit uterine cervical fibroblasts. Biol. Reprod. 36:277-281.

17. Powell, W. A., B. F. Mitchell, and J. R. Challis. 1986. Effect of steroids on progesterone output by explants of human chorion. Gynecol. Obstet. Invest. 22:64-72.

18. Wrighton, S. A., D. T. Molowa, and P. S. Guzelian. 1988. Identification of a cytochrome P-450 in human fetal liver related to glucocorticoid-inducible cytochrome P-450HLp in the adult. Biochem. Pharmacol. 37:3053-3055.

19. Kitada, M., and T. Kamataki. 1979. Partial purification and properties of cytochrome P450 from homogenates of human fetal livers. Biochem. Pharmacol. 28:793-797

20. Kitada, M., N. Igoshi, T. Kamataki, K. Itahashi, S. Imaoka, M. Komori, Y. Funae, T. Rikihisa, and Y. Kanakubo. 1988. Immunochemical similarity of P-450 HFLa, a form of cytochrome P-450 in human fetal livers, to a form of rat liver cytochrome P-450 inducible by macrolide antibiotics. Arch. Biochem. Biophys. 264:61-66.

21. Cresteil, T., P. Beaune, P. Kremers, J. P. Flinois, and J. P. Leroux. 1982. Drug-metabolizing enzymes in human fetal liver: partial resolution of multiple cytochromes P 450. Pediatr. Pharmacol. 2:199-207.

22. Kitada, M., T. Kamataki, K. Itahashi, T. Rikihisa, and Y. Kanakubo. 1987. Significance of cytochrome P-450 (P-450 HFLa) of human fetal livers in the steroid and drug oxidations. Biochem. Pharmacol. 36:453-456.

23. Kitada, M., T. Kamataki, K. Itahashi, T. Rikihisa, and T. Kanakubo. 1987. P-450 HFLa, a form of cytochrome P-450 purified from human fetal livers, is the $16 \alpha$-hydroxylase of dehydroepiandrosterone 3-sulfate. J. Biol. Chem. 262:13534-13537.

24. Komori, M., K. Nishio, H. Ohi, M. Kitada, and T. Kamataki. 1989. Molecular cloning and sequence analysis of cDNA containing the entire coding region for human fetal liver cytochrome P-450. J. Biochem. (Tokyo). 105:161163.

25. Komori, M., K. Nishio, M. Kitada, K. Shiramatsu, K. Muroya, M. Soma, K. Hagashima, and T. Kamataki. 1990. Fetus-specific expression of a form of cytochrome P-450 in human livers. Biochemistry. 29:4430-4433.

26. Lambert, M., and G. W. Pennington. 1965. The estimation of polar steroids in liquor amnii. J. Endocrinol. 32:287-293.

27. Lambert, M., and G. W. Pennington. 1965. 6B-Hydroxycortisol (4-preg- 
nane-6B,11B,17a,21-tetrol-3-20 dione) in liquor amnii. Nature (Lond.) 197:391-392.

28. Romano, W. M., L. A. Lukash, J. R. Challis, and B. F. Mitchell. 1986. Substrate utilization for estrogen synthesis by human fetal membranes and decidua. Am. J. Obstet. Gynecol. 155:1170-1175.

29. Noyes, R. N., A. T. Hering, and J. Rock. 1992. Dating the endometrial biopsy. Fertil. Steril. 1:3-25.

30. Wrighton, S. A., P. E. Thomas, P. Willis, S. L. Maines, P. B. Watkins, W. Levin, and P. S. Guzelian. 1987. Purification of a human liver cytochrome P-450 immunochemically related to several cytochromes $P-450$ purified from untreated rats. J. Clin. Invest. 80:1017-1022.

31. Wrighton, S. A., P. Maurel, E. G. Schuetz, P. B. Watkins, B. Young, and P. S. Guzelian. 1985. Identification of the cytochrome P-450 induced by macrolide antibiotics in rat liver as the glucocorticoid responsive cytochrome $\mathrm{P}-450 \mathrm{p}$. Biochemistry. 24:2171-2178.

32. Watkins, P. B., S. A. Wrighton, P. Maurel, E. G. Schuetz, G. Mendez-Picon, G. A. Parker, and P. S. Guzelian. 1985. Identification of an inducible form of cytochrome P-450 in human liver. Proc. Natl. Acad. Sci. USA. 82:6310-6314.

33. Molowa, D. T., E. G. Schuetz, S. A. Wrighton, P. B. Watkins, P. Kremers, G. Mendez-Picon, G. A. Parker, and P. S. Guzelian. 1986. Complete cDNA sequence of a cytochrome P-450 inducible by glucocorticoids in human liver. Proc. Natl. Acad. Sci. USA. 83:5311-5315.

34. Kauma, S., D. Matt, S. Strom, D. Eierman, and T. Turner. 1992. Interleukin-1B, human leukocyte antigen HLA-DRa, and transforming growth factor-B expression in endometrium, placenta, and placental membranes. Am. J. Obstet. Gynecol. 163:1430-1437.

35. Schuetz, J. D., D. T. Molowa, and P. S. Guzelian. 1989. Characterization of a cDNA encoding a new member of the glucocorticoid-responsive cytochromes P450 in human liver. Arch. Biochem. Biophys. 274:355-365.

36. Suggs, S. V., T. Hirose, T. Miyake, E. H. Kawashima, M. J. Johnson, K. Itakura, and R. B. Wallace. 1981. Developmental Biology Using Purified Genes. Academic Press, New York. 683 pp.

37. Messing, J. 1983. New M13 vectors for cloning. Methods Enzymol. 101:20-78.

38. Sanger, F., S. Nicklen, and A. R. Coulson. 1977. Sequencing with chainterminating inhibitors. Proc. Natl. Acad. Sci. USA. 74:5463-5467.

39. Devereux, J., P. Haeberli, and O. M. Smithies. 1984. A comprehensive set of sequence analysis programs for the VAX. Nucleic. Acids Res. 12:387-395.

39. Devereux, J., P. Haeberli, and Smithies. 1984. A comprehensive set of sequence analysis programs for the VAX. Nucleic. Acids Res. 12:387-395.

40. Beaune, P. H., D. R. Umbenhauer, R. W. Bork, R. S. Lloyd, and F. P. Guengerich. 1986. Isolation and sequence determination of a cDNA clone related to human cytochrome P-450 nifedipine oxidase. Proc. Natl. Acad. Sci. USA. 83:8064-8068.

41. Wrighton, S. A., and M. Vandenbranden. 1989. Isolation and characterization of human fetal liver cytochrome P450HLp2: a third member of the P450II gene family. Arch. Biochem. Biophys. 268:144-151.

42. Wrighton, S. A., B. J. Ring, P. B. Watkins, and M. Vandenbranden. 1989. Identification of a polymorphically expressed member of the human cytochrome P-450III family. Mol. Pharmacol. 36:97-105.

43. Bork, R. W., T. Muto, P. H. Beaune, P. K. Srivastava, R. S. Lloyd, and F. P. Guengerich. 1989. Characterization of mRNA species related to human liver cytochrome $\mathrm{P}-450$ nifedipine oxidase and the regulation of catalytic activity. J. Biol. Chem. 264:910-919.

44. Komori, M., K. Nishio, T. Fujitani, H. Ohi, M. Kitada, S. Mima, K. Itahashi, and T. Kamataki. 1989. Isolation of a new human fetal liver cytochrome P450 cDNA clone: evidence for expression of a limited number of forms of cytochrome P450 in human fetal livers. Arch. Biochem. Biophys. 272:219-225.

45. Waxman, D. J., C. Attisano, F. P. Guengerich, and D. P. Lapenson. 1988. Human liver microsomal steroid metabolism: identification of the major microsomal steroid hormone 6 beta-hydroxylase cytochrome P-450 enzyme. Arch. Bio chem. Biophys. 263:424-436.

46. Ged, C., J. M. Rouillon, L. Pichard, J. Combalbert, N. Bressot, P. Bories, H. Michel, P. Beaune, and P. Maurel. 1989. The increase in urinary excretion of $6 \beta$-hydroxycortisol as a marker of human hepatic cytochrome P450IIIA induction. Br. J. Clin. Pharmacol. 28:373-387.

47. Schuetz, E. G., and P. S. Guzelian. 1984. Induction of cytochrome P-450 by glucocorticoids in rat liver. II. Evidence that glucocorticoids regulate induction of cytochrome P-450 by a nonclassical receptor mechanism. J. Biol. Chem. 259:2007-2012.

48. Watkins, P. B., S. A. Wrighton, E. G. Schuetz, P. Maurel, and P. S. Guzelian. 1986. Macrolide antibiotics inhibit the degradation of the glucocorti- coid-responsive cytochrome $\mathrm{P}-450 \mathrm{p}$ in rat hepatocytes in vivo and in primary monolayer culture. J. Biol. Chem. 261:6264-6271.

49. Hostetler, K. A., S. A. Wrighton, D. T. Molowa, P. E. Thomas, W. Levin, and P. S. Guzelian. 1989. Coinduction of multiple hepatic cytochrome P-450 proteins and their mRNAs in rats treated with imidazole antimycotic agents Mol. Pharmacol. 35:279-285.

50. Schuetz, E. G., S. A. Wrighton, S. H. Safe, and P. S. Guzelian. 1986 Regulation of cytochrome P-450p by phenobarbital and phenobarbital-like inducers in adult rat hepatocytes in primary monolayer culture and in vivo. Biochemistry. 25:1124-1133.

51. Stehr-Green, P. A., E. Welty, G. Steele, and K. Steinberg. 1986. Evaluation of potential health effects associated with serum polychlorinated biphenyl levels. Environ. Health Perspect. 70:255-260.

52. Pasanen, M., and O. Pelkonen. 1990. Human placental xenobiotic and steroid biotransformations catalyzed by cytochrome P450, expoxide hydrolase, and glutathione s-transferase activities and their relationships to maternal cigarette smoking. Drug. Metab. Rev. 21:427-461.

53. Pacifici, G. M., and A. Rane. 1983. Epoxide hydroxylase in human placenta at different stages of pregnancy. Dev. Pharmacol. Ther. 6:83-93.

54. Waxman, D. J., P. A. Ram, G. Notani, G. A. Leblanc, J. A. Alberta, J. J. Morrissey, and S. S. Sundseth. 1990. Pituitary regulation of the male-specific steroid 6 $\beta$-hydroxylase P-450 2a (gene product IIIA2) in adult rat liver. Suppressive influence of growth hormone and thyroxine acting at a pretranslational level. Mol. Endocrinol. 4:447-454.

55. Burger, H.-J., J. D. Schuetz, E. G. Schuetz, and P. S. Guzelian. 1992. Paradoxical transcriptional activation of rat liver cytochrome P450 3A1 by dexamethasone and the antiglucocorticoid pregnenolone 16 alpha-carbonitrile: analysis by transient transfection into primary monolayer cultures of adult rat hepatocytes. Proc. Natl. Acad. Sci. USA. 89:2145-2149.

56. Beach, D. L., J. D. Schuetz, and P. S. Guzelian. 1991. Analysis of the expression of cytochrome P450 3A7 (HFLA) in HEPG2 cultures by a semiquantitative polymerase chain reaction method. FASEB (Fed. Am. Soc. Exp. Biol.) J. 6:1951.

57. Beach, D. L., J. D. Schuetz, and P. S. Guzelian. 1992. Regulation of expression of cytochrome P450 HFLA by dexamethasone in the human hepatoblastoma HEP G2. FASEB (Fed. Am. Soc. Exp. Biol.) J. 6:1951.

58. Csaba, G., and A. Inczefi-Gonda. 1989. Specificity of the dexamethasoneinduced steroid receptor in tetrahymena. Experientia (Basel). 45:174-175.

59. Ko, M. S. H., H. Nakauchi, and N. Takahashi. 1990. The dose dependence of glucocorticoid-inducible gene expression results from changes in the number of transcriptionally active templates. $E M B O$ (Eur. Mol. Biol. Organ.) J. 9:2835-2842.

60. Kauppila, A., R. Tuimala, O. Ylikorkala, M. Reinila, and P. Ylostalo. 1979. Placental steroid synthesis from DHEAS during dexamethasone therapy. Obstet. Gynecol. 54:39-42.

61. Rabe, T., R. Hosch, and B. Runnebaum. 1983. Diagnosis of intrauterine fetal growth retardation (IUGR) and placental insufficiency by a dehydroepiandrosterone sulfate (DHAS) loading test. Biol. Res. Pregnancy Perinatol. 4:130136.

62. Schulz, S., R. C. Klann, S. Schonfeld, and J. W. Nyce. 1992. Mechanisms of cell growth inhibition and cell cycle arrest in human colonic adenocarcinoma cells by dehydroepiandrosterone: role of isoprenoid biosynthesis. Cancer Res. 52:1372-1376.

63. Shimada, T., and F. P. Guengerich. 1989. Evidence for cytochrome P-450NF, the nifedipine oxidase, being the principal enzyme involved in the bioactivation of aflatoxins in human liver. Proc. Natl. Acad. Sci. USA. 86:462465.

64. Kitada, M., M. Taneda, H. Ohi, M. Komori, K. Itahashi, M. Nagao, and T. Kamataki. 1989. Mutagenic activation of aflatoxin B1 by P-450 HFLa in human fetal livers. Mutat. Res. 227:53-58.

65. Shimada, T., M. Iwasaki, M. V. Martin, and F. P. Guengerich. 1989. Human liver microsomal cytochrome p-450 enzymes involved in the bioactivation of procarcinogens detected by umu gene response in Salmonella typhimurium TA 1535/pSK1002. Cancer Res. 49:3218-3228.

66. Kitada, M., M. Taneda, K. Ohta, K. Hagashimi, K. Itahashi, and T. Kamataki. 1990. Metabolic activation of aflatoxin B1 and 2-amino-3-methylimidazo[4,5-f]-quinoline by human adult and fetal livers. Cancer Res. 50:26412645.

67. McManus, M. E., W. M. Burgess, M. E. Veronese, A. Huggett, L. C. Quattrochi, and R. H. Tukey. 1990. Metabolism of 2-acetylaminofluorene and benzo(a)pyrene and activation of food-derived heterocyclic amine mutagens by human cytochromes P-450. Cancer Res. 50:3367-3376. 